\title{
Virtual Reality to Improve Motor Function After Stroke: Past, Present, and Future
}

\author{
John 0 Brien ${ }^{1,2}$, * David Roberts ${ }^{1,2}$ and Kenneth Monaghan ${ }^{1,2}$ \\ ${ }^{1}$ Department of Neurology, Clinical Health and Nutrition Centre (CHANCE), Ireland \\ ${ }^{2}$ Department of Neurology, Neuroplasticity Research Group, Clinical Health and Nutrition Centre (CHANCE), Ireland
}

Submission: March 07, 2019; Published: March 18, 2019

*Corresponding author: John O Brien, Department of Neurology, Clinical Health and Nutrition Centre (CHANCE), Neuroplasticity Research Group, School of Science, Institute of Technology (IT) Sligo, Ireland

Keywords: Rehabilitation; Virtual reality; Health organization; stroke; Trauma; Environment; Motor function; Technology; Neuroplasticity; Therapy; Recruitment

\section{Introduction}

The World Health Organization report that 15 million people worldwide suffer stroke each year, with stroke being the third leading cause of disability worldwide [1]. In Ireland stroke is the leading cause of disability with 5000-6000 new stroke survivors each year requiring rehabilitation [2]. As rehabilitation and clinical experience has become more sophisticated, behavioral activity has become a central principle to modulating the plasticity of the brain post stroke [3]. Traumatic injury to the adult brain such as ischemia creates an environment "ripe for malleability and axonal growth" similar to the developmental stages of the brain i.e. childhood [3]. Behavioral activity through rehabilitation is central to returning pre-stroke function with the greater part of rehabilitation generally aimed at the preliminary stages of recovery i.e. the first three months [4]. Previous thinking lead authors to believe that recovery of motor function could only occur in the first three months post trauma $[5,6]$. However, research now shows intensive rehabilitation can improve function in both the acute (i.e. first three months post trauma) and chronic (i.e. greater than three months) stages of stroke [6]. For neuroplasticity and axonal growth to occur rehabilitation needs to be challenging, motivating, salient, repetitive and intensive $[7,8]$.

While clinical rehabilitation programmes have been proven effective in motor re-learning, barriers exist in the sustainability of regular and repetitive behavioral activities. Barriers include; post stroke clinical rehabilitation services often being inadequately resourced and above capacity which results in insufficient rehabilitation time for the patient [9]. Another obstacle to effective rehabilitation is patient motivation with repetitive training in itself often described by patients as boring and time consuming [10]. The optimal dose of repetitions is estimated to be in the hundreds if not thousands, but this is not being achieved in clinical practice [11]. Sub optimal rehabilitation time combined with 7 out of 10 of patients receiving no further treatment or care on release from the care setting [12] leaves a large gap in maximizing behavioral activity time to maximize neuroplastic adaptations.

\section{Innovative solutions to rehabilitation barriers}

With recent advancements in digital technology; gaming and virtual reality are attracting much attention as innovative solutions to the resourcing and motivational challenges facing conventional clinical stroke therapy. Built upon advances in tracking devices and improved imagery quality, virtual reality environments elicit a substantial feeling of realness to the user when immersed in an artificial world [13]. These digital advances, combined with greater access and affordability, has led to the proposal that gaming in a virtual reality environment can be a motivating and safe way of prolonging rehabilitation therapy both in the clinical and home setting [14]. Gaming literature shows it has the potential for creating environments that are enriched, motivating, repetitive, adhered to and selfmanaging, all key components in increasing behavioral activity and stimulating neuroplasticity [15]. Games and play based interventions are now being used to make rehabilitation more enjoyable which in turn promotes motivation and increased repetition [10]. 


\section{Open Access Journal of Neurology \& Neurosurgery}

Initial observations are showing positive results when comparing the feasibility of virtual reality therapy to conventional stroke rehabilitation and control groups. A 2012 Randomized Control Trial (RCT) feasibility study $[16,17]$ carried out on patients over a 3-week period showed a 7/100 \& 8/100-point improvement in upper limb Motricity Index scores for the virtual reality therapy group and a conventional therapy group respectively [18]. At 6 weeks follow up the virtual reality group had maintained improvements whilst the conventional therapy group had not however to be considered clinically relevant a change of 10 points would be needed on the Motricity index [16]. The trial demonstrated a high compliance with members completing all therapy sessions which in some way may explain the positive albeit non-significant results $[17,9]$. The study did not show any clinical or statistical significance over conventional therapy however this trial did demonstrate that VR is a safe and acceptable form of therapy for chronic stroke patients.

In a 2017 feasibility RCT, the intervention was based on motor learning theory, aimed at increasing numbers of repetitions of functional movements through VR games that encouraged pronation \& supination, grasp \& release and reach \& grasp. The control group received no dose, they only received visits to collect outcome measures [17]. The trial showed significant differences at study midpoint in Wolf Grip strength and two sub scales of the Motor Activity Log over an 8-week intervention in favor of the intervention group. However low recruitment rates meant a small sample size and difficulty interpreting results mean the data must be treated with caution [17]. Possible reasons for a difference at mid-point was that researchers appeared to spend considerably more time with the intervention group (Median per participant 6 hrs 10 mins). Time spent with the control group was not recorded.

While the evidence is far from conclusive and would appear contradictory at times, the value of virtual reality may not lie in replacing conventional therapy but in providing an alternative method of therapy that increases rehabilitation activity time and motivates users into repetitive practice. Such a therapy would be even more advantageous in the subacute and chronic phases of recovery when patients have limited access to further rehabilitation [16].

\section{Defining Virtual Reality}

Developed first in the 1960s, virtual reality has been popularized in recent years and has become widely accessible through commercial gaming systems. Virtual reality is the use of "interactive simulations created with computer hardware and software to present users with opportunities to engage in environments that appear and feel similar to real world objects and events" [18]. Virtual reality is often described as both immersive and non-immersive. Immersive virtual reality is where the user is part of the environment or egocentric. Nonimmersive virtual reality is where the user is outside of the virtual environment or exocentric [9] (Table 1).
Table 1: Examples of Commercial Non-immersive and immersive virtual reality systems (the year these systems were made commercially available)

\begin{tabular}{|c|c|}
\hline Non-Immersive virtual reality & Immersive virtual reality \\
\hline (commercially available) & (commercially available) \\
\hline Playstation Eyetoy (2004) & Google Cardboard (2014) \\
\hline Nintendo Wii (2006) & Samsung Gear VR (2015) \\
\hline Xbox Kinect (2010) & Occulus Rift (2016) \\
\hline GestureTek IREX (2001) & Windows Mixed Reality (2017) \\
\hline
\end{tabular}

For neuro-rehabilitation purposes the term virtual reality is sometimes improperly used [19]. Subjects using virtual reality should feel embedded/immersed within a synthetic environment that looks, feels, sounds and reacts with real time movements in a natural way [19]. Non-immersive video games and rehabilitation devices using TV/computer monitors and controllers to mimic movements are not virtual reality as they do not immerse the subject into a virtual environment [20]. In a virtual environment the user should be able to move around a virtual world, see it from different angles, reach into it, grab it and reshape it $[20,21]$.

\section{Virtual Reality, Gaming and Stroke Rehabilitation}

With the speed of technological advancement in virtual reality the evidence for its application in the rehabilitation setting is limited. To date several systematic reviews have been carried out examining the efficacy of virtual reality use in the clinical rehabilitation setting [4,7,15,22-25]. The extent of pace of advancement in this area can be demonstrated by the Cochrane Review updates by Laver and Colleagues. The 2017 review identified 72 studies compared with 36 studies in the 2015 update and in the original review in 2011 [19,7].

In each of the systematic reviews referenced in the last paragraph similar conclusions were reached; studies to date have found that virtual reality therapy may be beneficial in improving motor recovery when compared to conventional therapy however the lack of quality evidence demonstrates the need for more robust randomized controlled trials with larger study numbers. A number of possible hypotheses why virtual reality may work include; its features provide users with a more interesting and enriched environment and tasks that are goal orientated this in turn appears to increase enjoyment and better problem solving thereby encouraging a higher number of repetitions [21]. On a neuro-physiological level though imaging and recording of neural activity virtual reality has demonstrated greater neural activation, cortical spinal excitability and recruitment of contralateral \& ipsilateral regions of the brain [21]. In their most recent review however the findings would appear to conflict with earlier conclusions [4]. This review included 72 trials with 2470 participants and found that virtual reality did not improve upper arm function (22 trials) and did not improve walking speed ( 6 trials) when compared to conventional therapy. There was slight evidence to 
show an improvement in activities for daily living however it is pointed out this data needs to be treated with caution due to low or moderate quality evidence.

In a 2016 review of the literature on virtual reality for upper extremity rehabilitation in stroke patients many issues have been highlighted, most notably, a lack of standardization in study design, small sample sizes and the varying degrees of immersion that exist in virtual reality technology [24,25]. The term virtual reality also can be used quite broadly to describe a number of types of devices and software and in some cases is often used incorrectly which highlights the need for a more accurate descriptions and subgroups for the technology when it comes to the application of virtual reality for rehabilitation and research purposes [26].

\section{The Future for home-based stroke rehabilitation us- ing Virtual Reality}

In developed countries such as the US, Canada, United Kingdom and Ireland it is well documented the shortfall in meeting the rehabilitation needs of stroke survivors $[2,12,27]$. In a 2012 review article on "Seven Capital Devices for the Future of Stroke Rehabilitation", virtual reality has been identified as a tool that could bring stroke rehabilitation into the home setting [19], thereby increasing rehabilitation time. There are many advantages for the use of virtual reality as a stroke rehabilitation tool; it's system can be designed and changed to the needs and abilities of the user, it provides a motivating stimulus within a safe environment ultimately promoting repetition and adherence to the rehabilitation program [19].

With the need for larger, more robust randomized control trials with clearer definitions on the type of virtual reality system being used replacing conventional therapy with virtual reality therapy is not practical. However, the strength of virtual reality does not lie in its ability to promote neuroplasticity. Its strength lies in its ability to provide a safe and salient environment that motivates the patient to perform high numbers of repetitions, increasing behavioral activity which in turn promotes neuroplastic adaptations.

\section{Existing research and the future for IT Sligo's Neuro- plasticity Group}

The Neuroplasticity Research Group at Institute of Technology (IT) Sligo has been in existence since 2012 under the direction and supervision of Dr Kenneth Monaghan. The group is located within the Clinical Health and Nutrition Centre (CHANCE) at the IT and is part of an international collaborative network that focuses on the interaction of limbs to improve rehabilitation outcomes after neurological impairment and orthopedic injuries through innovative neuroplastic treatments. Rehabilitation principles have been demonstrated through pilot RCT's in the cross education of muscle, and mirror therapy. An upcoming pilot RCT study will investigate the potential for using Immersive VR to enhance existing neuroplasticity principles post stroke in the patient's own home. Please contact us if you have a future interest in collaboration in these areas.

\section{References}

1. (2017) World Health Organization Rehabilitation 2030: A call for action. Meeting report 93.

2. (2014) ESRI. Towards Earlier Discharge, Better Outcomes, Lower Cost: Stroke Rehabilitation in Ireland. Irish Hear Found.

3. Nudo RJ (2013) Recovery after brain injury: mechanisms and principles. 7:887.

4. Laver KE, Lange B, George S, Je D, Saposnik G, et al. (2018) Virtual reality for stroke rehabilitation (Revie) 11: CD008349.

5. Biernaskie J, Chernenko G, Corbett D (2004) Efficacy of Rehabilitative Experience Declines with Time after Focal Ischemic Brain Injury. J Neurosci 24(5): 1245-1254.

6. Krakauer JW, Carmichael ST (2017) Broken Movement: The Neurobiology of Motor Recovery after Stroke. MA: The MIT Press, Cambridge, UK.

7. Saposnik G, Levin M (2011) Virtual reality in stroke rehabilitation: A meta-analysis and implications for clinicians. Stroke 42(5): 13801386.

8. Overman JJ, Clarkson AN, Wanner IB, Overman WT, Eckstein I, et al. (2012) A role for ephrin-A5 in axonal sprouting, recovery, and activitydependent plasticity after stroke 109(33): 1-10.

9. Luis MAVS, Atienza RO, Luis AMS (2016) Immersive Virtual Reality as a Supplement in the Rehabilitation Program of Post-Stroke Patients. $10^{\text {th }}$ Int Conf Next Gener Mob Appl Secur Technol 47-52.

10. Saywell N, Taylor N, Rodgers E, Skinner L, Boocock M (2017) Playbased interventions improve physical function for people with adultacquired brain injury: A systematic review and meta-analysis of randomised controlled trials. Clin Rehabil 31(2): 145-157.

11. Connell LA, Mcmahon NE, Redfern J, Watkins CL, Eng JJ (2015) Development of a behavior change intervention to increase upper limb exercise in stroke rehabilitation 10: 34 .

12. (2017) Stroke Association State of the Nation Stroke statistics. Stroke Assoc Resour Sheet: 1-37.

13. Adamovich SV, August K, Merians A, Tunik E (2009) A virtual realitybased system integrated with fmri to study neural mechanisms of action observation-execution: A proof of concept study. Restor Neurol Neurosci 27(3): 209-223.

14. Hung YX, Huang PC, Chen KT, Chu WC (2016) What do stroke patients look for in game-based rehabilitation: A survey study. Med (United States) 95(11): e3032.

15. Hatem SM, Saussez G, Della Faille M, Prist V, Zhang X, et al. (2016) Rehabilitation of Motor Function after Stroke: A Multiple Systematic Review Focused on Techniques to Stimulate Upper Extremity Recovery. Front Hum Neurosci 10: 1-22.

16. Crosbie JH, Lennon S, McGoldrick MC, McNeill M, McDonough SM (2012) Virtual reality in the rehabilitation of the arm after hemiplegic stroke: A randomized controlled pilot study. Clin Rehabil 26(9): 798806.

17. Standen PJ, Threapleton K, Richardson A, Connell L, Brown DJ, et al. (2017) A low-cost virtual reality system for home-based rehabilitation of the arm following stroke: A randomized controlled feasibility trial. Clin Rehabil 31(3): 340-350.

18. Weiss PL, Katz N (2004) The potential of virtual reality for rehabilitation. J Rehabil Res Dev 41(5): vii-x. 
19. Iosa M, Morone G, Fusco A, Bragoni M, Coiro P, et al. (2012) Seven capital devices for the future of stroke rehabilitation. Stroke Res Treat 2012: 187965.

20. Tieri G, Morone G, Paolucci S, Iosa M (2018) Virtual reality in cognitive and motor rehabilitation: facts, fiction and fallacies. Expert Rev Med Devices 15(2): 107-117.

21. Laver KE, George S, Thomas S, Deutsch JE, Crotty M (2017) Virtual reality for stroke rehabilitation. Cochrane Database Syst Rev (2): CD008349.

22. Crosbie JH, Lennon S, Basford JR, McDonough SM (2007) Virtual reality in stroke rehabilitation: Still more virtual than real. Disabil Rehabil 29(14): 1139-1146.

23. Lohse KR, Hilderman CGE, Cheung KL, Tatla S, Van Der Loos HF (2014) Virtual Reality Therapy for Adults Post-Stroke: A Systematic Review

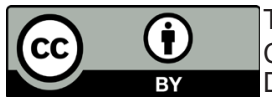

This work is licensed under Creative Commons Attribution 4.0 Licens

DOI: 10.19080/OAJNN.2019.10.555785 and Meta-Analysis Exploring Virtual Environments and Commercial Games in Therapy. PLoS One 9(3): 1-13.

24. Yates M, Kelemen A, Sik Lanyi C (2016) Virtual reality gaming in the rehabilitation of the upper extremities post-stroke. Brain Inj 30(7): 855-863.

25. Thomson K, Pollock A, Bugge C, Brady M (2014) Commercial gaming devices for stroke upper limb rehabilitation: A systematic review. Int J Stroke 9(4): 479-488.

26. Tieri G, Morone G, Paolucci S, Iosa M (2018) Virtual reality in cognitive and motor rehabilitation: facts, fiction and fallacies. Expert Rev Med Devices 15(2): 107-117.

27. Allen L, John-Baptiste A, Meyer M, Richardson M, Speechley M, et al. (2018) Assessing the impact of a home-based stroke rehabilitation programme: a cost-effectiveness study. Disabil Rehabil 10: 1-6.

\section{Your next submission with Juniper Publishers will reach you the below assets}

- Quality Editorial service

- Swift Peer Review

- Reprints availability

- E-prints Service

- Manuscript Podcast for convenient understanding

- Global attainment for your research

- Manuscript accessibility in different formats ( Pdf, E-pub, Full Text, Audio)

- Unceasing customer service

Track the below URL for one-step submission https://juniperpublishers.com/online-submission.php 